\title{
Association between household size, residential area, and osteoporosis: analysis of 2008 to 2011 Korea National Health and Nutrition Examination Survey
}

\author{
Sung-Woo Kim ${ }^{1,}$, Kwi-Hyun Bae ${ }^{1, *}$, Jung-Beom Seo ${ }^{1}$, Jae-Han Jeon ${ }^{1}$, Won-Kee Lee ${ }^{2}$, In-Kyu Lee ${ }^{1}$, \\ Jung-Guk Kim ${ }^{1}$, and Keun-Gyu Park ${ }^{1}$
}

${ }^{1}$ Division of Endocrinology and Metabolism, Department of Internal Medicine, ${ }^{2}$ Department of Preventive Medicine, Kyungpook National University School of Medicine, Daegu, Korea

Received: August 12, 2015 Revised : November 23, 2015 Accepted: January 23, 2016

\section{Correspondence to}

\section{Keun-Gyu Park, M.D.}

Division of Endocrinology and Metabolism, Department of Internal Medicine, Kyungpook National University School of Medicine, 130 Dongdeok-ro, Jung-gu, Daegu 41944, Korea

Tel: $+82-53-200-6953$

Fax: +82-53-426-6722

E-mail:kpark@knu.ac.kr

*These authors contributed equally to this work.
Background/Aims: The prevalence of single-person households has rapidly increased in Korea. Individuals living alone and in rural areas may have a higher risk of various metabolic diseases due to differences in lifestyle. However, few studies have investigated the association of household size and residential area with health-related problems. This study aimed to evaluate the association of household size and residential area with risk of osteoporosis in postmenopausal women.

Methods: This cross-sectional study enrolled 3,058 postmenopausal women from the 2008 to 2011 Korea National Health and Nutrition Examination Survey (KNHANES). We examined the association between bone mineral density (BMD) and household size and residential area.

Results: Individuals living in rural areas had significantly lower BMD of the lumbar spine than those living in an urban area. Subsequently, we divided the participants into four groups according to household size and residential areas. Lumbar spine BMD was significantly lower in individuals living in rural singleperson households than those in urban households with two or more individuals, even after adjustment for multiple confounding factors. In addition, individuals in rural single-person households had significantly greater odds of osteoporosis in the lumbar spine than those in urban households with two or more residents.

Conclusions: Individuals in rural single-person households had significantly lower BMD and greater odds of osteoporosis in lumbar spine than urban households with two or more individuals. The results of this study suggest that individuals living in rural single-person households may benefit from more careful screening for osteoporosis.

Keywords: Single household; Rural resident; Osteoporosis; Bone density; Postmenopausal women

\section{INTRODUCTION}

In recent years, the proportion of single-person households has rapidly increased in Korea from $23.9 \%$ in 2010 to $25.3 \%$ in 2012 and $27.1 \%$ in 2015 [1,2]. Many factors are attributed to this increase, including divorce, spousal death, and a greater number of individuals moving to urban areas [3]. One study conducted in England also 
shows a consistent increase in the proportion of single households, although the reasons for this increase are not fully understood [4].

Increase in proportion of single-person households has been associated with various social and health problems. Individuals living alone are more likely to smoke and drink [5], and several studies show that single elderly people have poor nutrient intake [6], which may lead to protein and calcium deficiencies that affect bone metabolism and increase the risk of osteoporosis [7-10]. Although these problems have been recognized, few studies have evaluated the association between single households and the incidence of osteoporosis. Recently, one study investigated the association between socioeconomic status (SES) and osteoporosis in single-person households. In this study, the risk of osteoporosis was associated with SES in a different pattern in singleperson households versus households with two or more people [11].

Moreover, type of residential area may influence incidence of osteoporosis. Several studies report differences between urban and rural residence in the prevalence of osteoporosis [12-14], as Melton et al. [12] showed that overall fracture rates were $15 \%$ greater among residents in the central city of Rochester than in the rural portion of Olmsted County. Conversely, Filip and Zagorski [13] reports no significant difference in mean bone mineral density (BMD) between urban and rural populations. Thus, the association between area of residence and osteoporosis still remains unclear.

In this study, we investigated whether household size and residential area were associated with BMD and risk of osteoporosis in postmenopausal women using data from the fourth and fifth Korea National Health and Nutrition Examination Survey (KNHANES IV and V) conducted from 2008 to 2011.

\section{METHODS}

\section{Subjects}

This cross-sectional study was based on data acquired from the KNHANES in 2008, 2009, 2010, and 2011. KNHANES is a population-based nationwide survey conducted by Korea Centers for Disease Control and Prevention (IRB no.: 2008-04EXP-01-C, 2009-01CON-03-2C,
2010-02CON-21-C, and 2011-02CON-06-C). BMD was assessed in data collected from July 2008 to May 2011. A total of 21,071 subjects had available BMD measurements. A total of 4,991 postmenopausal women aged 45 years or older were included in the present analysis. Individuals who had a history of osteoporosis medication use, severe chronic kidney disease (estimated glomerular filtration rate $[\mathrm{GFR}]<30$ ), artificial menopause such as hysterectomy, and early menopause (age <30) were excluded. Subjects were also excluded if they did not have adequate data for BMD or blood samples. Finally, 3,058 postmenopausal women were analyzed in this study.

\section{BMD measurement}

BMD was measured in the lumbar spine, total femur, and femoral neck using dual-energy X-ray absorptiometry (DXA; QDR 4500A, Hologic Inc., Waltham, MA, USA). DXA instruments were calibrated as described previously [15], and reference values were obtained using this method. DXA calibrations were maintained via an internal referencing system [16]. Coefficients of variation for repeated measurements of $<1.9 \%$ for the lumbar spine, $<1.8 \%$ for the total femur, and $<2.5 \%$ for the femoral neck satisfied the precision criteria. BMD was analyzed using standard techniques by the Korean Society of Osteoporosis and Hologic Discovery software (version 13.1). Osteoporosis was defined as a T score $\leq-2.5$ standard deviation according to the World Health Organization criteria [17].

\section{Measurements of biochemical and clinical variables}

Body height was measured at corrected posture to the nearest $0.1 \mathrm{~cm}$. Body weight was measured in light clothes after zero correction to the nearest $0.1 \mathrm{~kg}$. Body mass index (BMI) was calculated as weight divided by height squared. Blood pressure (BP) was measured using a mercury sphygmomanometer (Baumanometer, W.A. Baum, Copiague, NY, USA). Blood samples were collected and transported to the Neodin Medical Institute in Seoul, Korea. Total cholesterol was measured from fasted blood samples with a Hitachi Automatic Analyzer 7600 (Hitachi, Tokyo, Japan). The levels of serum parathyroid hormone (PTH) were measured by chemiluminescence immunoassay (Diasorin Inc., Stillwater, MN, USA), and serum vitamin D was measured by radioimmunoassay (Diasorin) with a gamma coun- 
ter (1470 Wizard, PerkinElmer, Turku, Finland). GFR was calculated using the Modification of Diet in Renal Disease formula. The KNHANES consisted of a health interview survey, a health examination survey, and a nutrition survey. Personal medical data, which included the number of household members and area of residence, were collected using a questionnaire. Residential area was classified as urban and rural based on the administrative district. Menopause was defined as natural menopause without a history of hysterectomy or early menopause. Diabetes and hypertension (HTN) were defined in participants who had already been diagnosed. The health interview survey included the International Physical Activity Questionnaire to obtain information about smoking status, drinking status, and physical activity. Smoking status was classified as current smoker, ex-smoker, and non-smoker. Heavy alcoholics were defined as people who consumed $\geq 30 \mathrm{~g}$ of alcohol per day. Physical activity was classified as high physical activity for at least 20 minutes for 3 days per week, moderate activity for at least 30 minutes for 5 days per week, and walking activity for 30 minutes for 5 days per week. Dietary intake of food, total energy, protein, fat, and calcium was estimated using the 24 hours recall method and a food frequency questionnaire in the nutrition survey.

\section{Statistical analysis}

All data were presented as mean \pm standard error for continuous data and numbers and percentages for categorical data. Statistical analysis was performed using SPSS version 18.0 (SPSS Inc., Chicago, IL, USA). Clinical and demographic variables of subject groups were analyzed by Student $t$ test and chi-square test. Because the KNHANES was designed as a complex sample survey, we estimated BMD according to household size and residential area using a complex samples general linear model. The models were adjusted for age, BMI, number of pregnancies, menopause duration, systolic BP, PTH, vitamin D, HTN, thyroid disease, working hours, physical activity, heavy alcoholics, smoking status, daily food intake, and nutrient support. Subjects were divided into four groups according to household size and residential area, and baseline characteristics were compared using analysis of variance for continuous variables and chi-square tests for categorical variables. The odds ratio (OR) of osteoporosis and fracture was assessed in four groups using the complex samples logistic regression model. A $p<0.05$ was considered statistically significant.

\section{RESULTS}

\section{General characteristics of participants}

The general characteristics of the participants are presented in Table 1. A total of 969 women lived in a rural area (average age, 65.2 years) and the remaining 2,089 women lived in an urban area (average age, 62.4 years). Rural residents had higher systolic BP and vitamin D levels, while BMI, diastolic BP, fasting glucose, total cholesterol, and PTH levels did not differ between the two groups. Although there was no difference in total energy intake between the two groups, daily food, protein, fat, and calcium intakes were lower in rural residents. Urban residents worked fewer hours and included more current smokers. Physical activity and the number of heavy alcoholics did not differ between the two groups. The number of people per household was lower for rural residents, and the proportion of single-person households was $19.4 \%$ for rural residents and $13.2 \%$ for urban residents. The prevalence of HTN was higher in rural residents, while the prevalence of thyroid disease was higher in urban residents. Anti-hypertensive drug use, the diabetes mellitus prevalence, and cancer history were similar between the two groups. The proportion of people with osteoporosis was significantly higher in rural residents, but the difference in the proportion of people with vertebral fracture was not significant.

\section{Residential area and BMD}

Participants living in a rural area had a significantly lower BMD at the lumbar spine than those living in an urban area (Fig. 1A), whereas BMD in the total femur and femoral neck were not significantly different (Fig. ${ }_{1 B}$ and ${ }_{1 C}$ ). The lumbar spine BMD of rural residents remained significantly lower than that of other residents after adjustment for multiple confounding factors (Fig. 1A). The prevalence of lumbar spine osteoporosis was significantly higher in rural residents in the unadjusted model (Fig. 2A). There was no significance after adjustment of confounding factors in this association. Although the OR of vertebral fracture was also higher in rural residents than in urban residents, this was not 
Table 1. General characteristics of postmenopausal women in the 2008 to 2011 Korea National Health and Nutrition Examination Survey

\begin{tabular}{|c|c|c|c|}
\hline \multirow{2}{*}{ Characteristic } & \multicolumn{2}{|c|}{ Postmenopausal women $(\mathrm{n}=3,058)$} & \multirow{2}{*}{$p$ value } \\
\hline & Rural residents $(n=969)$ & Urban residents $(\mathrm{n}=2,089)$ & \\
\hline Age, yr & $65.2 \pm 0.3$ & $62.4 \pm 0.2$ & $<0.001$ \\
\hline $\mathrm{BMI}, \mathrm{kg} / \mathrm{m}^{2}$ & $24.1 \pm 0.1$ & $24.2 \pm 0.1$ & 0.233 \\
\hline $\mathrm{SBP}, \mathrm{mmHg}$ & $129.7 \pm 0.6$ & $127.7 \pm 0.4$ & 0.002 \\
\hline $\mathrm{DBP}, \mathrm{mmHg}$ & $78.2 \pm 0.3$ & $78.2 \pm 0.2$ & 0.926 \\
\hline Fasting glucose, mg/dL & $99 \cdot 7 \pm 0.7$ & $101.1 \pm 0.5$ & 0.269 \\
\hline Total cholesterol, mg/dL & $200.1 \pm 1.2$ & $202.0 \pm 0.8$ & 0.313 \\
\hline Vitamin D, ng/mL & $19.8 \pm 0.2$ & $17.7 \pm 0.2$ & $<0.001$ \\
\hline PTH, pg/mL & $70.7 \pm 1.1$ & $68.6 \pm 0.7$ & 0.133 \\
\hline Age at menopause, yr & $48.5 \pm 0.2$ & $49.7 \pm 0.1$ & $<0.001$ \\
\hline No. of pregnancies & $5.2 \pm 0.1$ & $4.8 \pm 0.1$ & $<0.001$ \\
\hline Food intake, g/day & $1,023.9 \pm 16.4$ & $1,153 \cdot 2 \pm 14.2$ & $<0.001$ \\
\hline \multicolumn{4}{|l|}{ Nutrient support } \\
\hline Total energy intake, kcal/day & $1,554.1 \pm 18.2$ & $1,568.2 \pm 13.8$ & 0.630 \\
\hline Protein intake, g/day & $50.3 \pm 0.9$ & $53.3 \pm 0.6$ & 0.005 \\
\hline Fat intake, g/day & $19.9 \pm 0.5$ & $24.2 \pm 0.4$ & $<0.001$ \\
\hline Calcium intake, mg/day & $400.4 \pm 9.7$ & $441.5 \pm 9.3$ & 0.012 \\
\hline Working hours, hr/wk & $27.7 \pm 0.8$ & $15.2 \pm 0.5$ & $<0.001$ \\
\hline Physical activity, high/moderate/walk & $\begin{array}{c}109 / 137 / 245 \\
(11.2 / 14.1 / 25 \cdot 2)\end{array}$ & $\begin{array}{c}241 / 180 / 634 \\
(11.5 / 8.6 / 30.3 .0)\end{array}$ & 0.202 \\
\hline Heavy alcoholics & $12(1.2)$ & $23(1.1)$ & 0.740 \\
\hline Cigarette smoking, current/ex & $22 / 43(2.3 / 4.4)$ & $93 / 76(4 \cdot 5 / 3 \cdot 6)$ & 0.029 \\
\hline Diabetes mellitus & $108(11.1)$ & $278(13 \cdot 3)$ & 0.094 \\
\hline Hypertension & $406(41.9)$ & $796(38.1)$ & 0.046 \\
\hline Anti-hypertensive drug use & $355(36.6)$ & $686(32.8)$ & 0.103 \\
\hline Thyroid disease & $53(5 \cdot 5)$ & $179(8.6)$ & 0.003 \\
\hline History of cancer & $40(4.1)$ & $85(4.1)$ & 0.916 \\
\hline No. of people per households & $2.4 \pm 0.0$ & $2.8 \pm 0.0$ & $<0.001$ \\
\hline Single-person households & $188(19.4)$ & $276(13.2)$ & $<0.001$ \\
\hline Osteoporosis & $406(41.9)$ & $646(30.9)$ & $<0.001$ \\
\hline Vertebral fracture & $17(1.8)$ & $20(1.0)$ & 0.091 \\
\hline
\end{tabular}

Values are presented as mean \pm SE or number (\%). All $p$ values were obtained using the Student $t$ test or chi-square test. BMI, body mass index; SBP, systolic blood pressure; DBP, diastolic blood pressure; PTH, parathyroid hormone.

statistically significant (Fig. 2B).

\section{General subject characteristics according to house- hold size and residential area}

We divided the subjects into the following four groups (Table 2): (1) single-person households in a rural area (single in rural, $\mathrm{n}=194$ ); (2) households with two or more people in a rural area (two-more in rural, $\mathrm{n}=775)$; (3) single-person households in an urban area (single in urban, $\mathrm{n}=297$ ); and (4) households with two or more people in an urban area (two-more in urban, $\mathrm{n}=1,792$ ). The mean age in the two-more in urban group was lower than in the other groups. BMI was lowest in the single in rural groups. Systolic BP was highest in the single urban group 

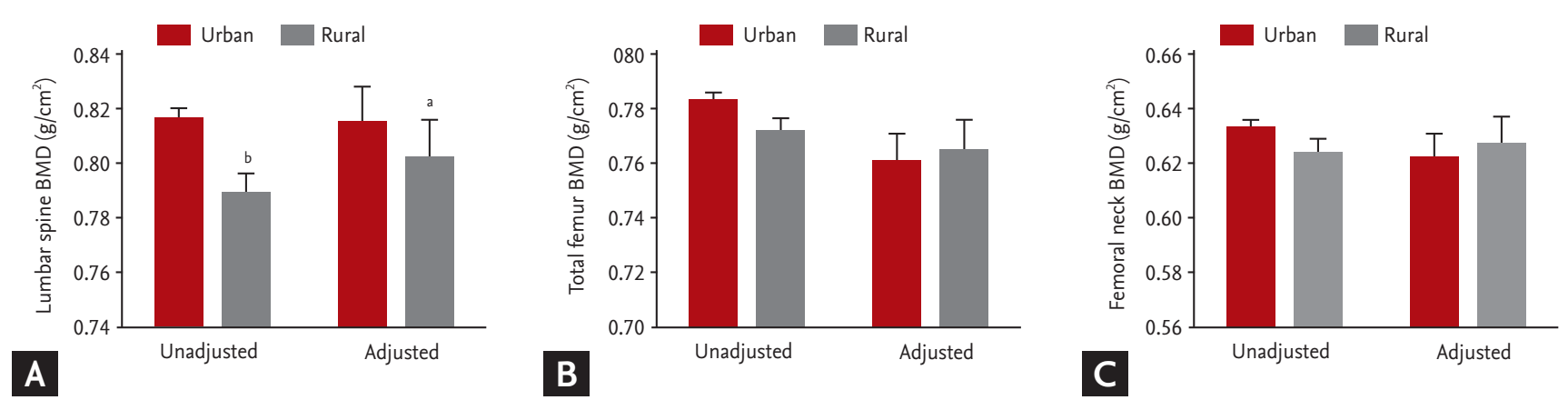

Figure 1. Association between residential area and bone mineral density (BMD) in (A) lumbar spine, (B) total femur, and (C) femoral neck. Adjusted model: for age, body mass index, number of pregnancies, duration of menopause, systolic blood pressure, parathyroid hormone, vitamin D levels, hypertension, thyroid disease, working hours, physical activity, heavy alcoholics, smoking status, daily food intake, and nutrient support. Data were analyzed by complex samples general linear model. ${ }^{\mathrm{a}} \mathrm{p}<0.01$ (statistical significance), ${ }^{\mathrm{b}} \mathrm{p}<0.05$ (statistical significance).
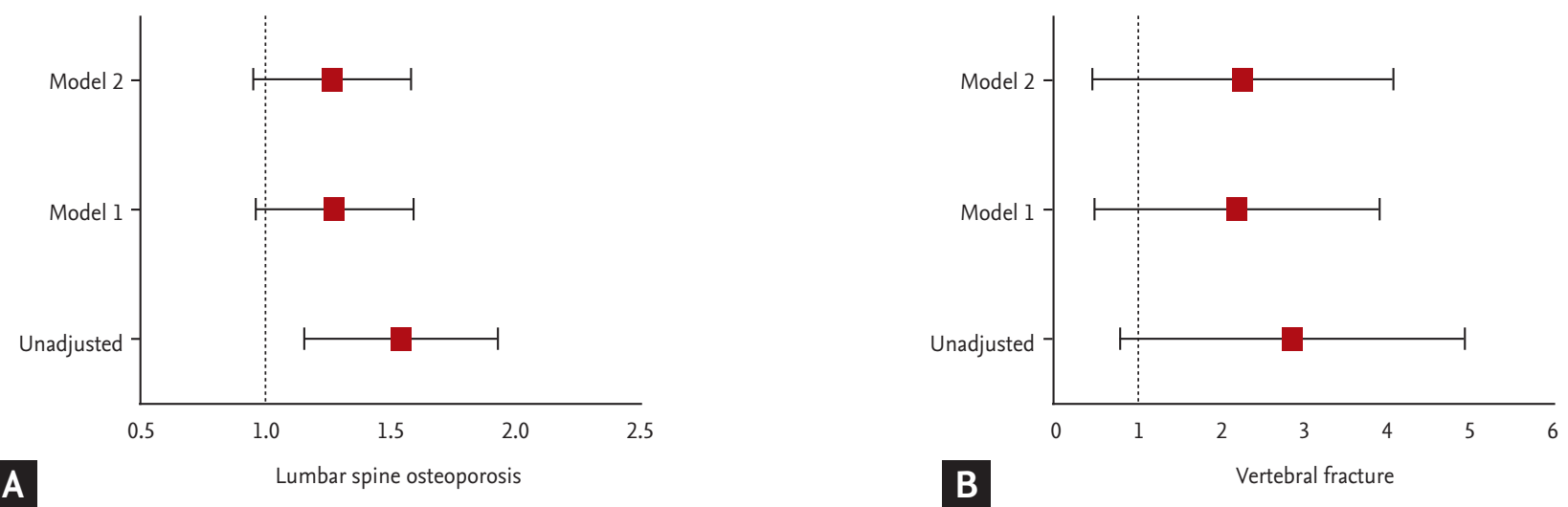

Figure 2. Association between residential area and (A) lumbar spine osteoporosis and (B) vertebral fracture. Model 1: adjusted for age, body mass index, number of pregnancies, duration of menopause, systolic blood pressure, parathyroid hormone, vitamin D levels, hypertension, and thyroid disease. Model 2: adjusted for age, body mass index, number of pregnancies, duration of menopause, systolic blood pressure, parathyroid hormone, vitamin D levels, hypertension, thyroid disease, working hours, physical activity, heavy alcoholics, smoking status, daily food intake, and nutrient support. Data were analyzed by the complex samples logistic regression model. All data are expressed as odds ratio ( $95 \%$ confidence interval).

and lowest in the two-more in urban group. Diastolic $\mathrm{BP}$, fasting glucose, and total cholesterol were not statistically different among the groups. Vitamin D and PTH levels tended to be highest in the single in rural group. Subjects in the single in rural group reached menopause at a younger age and had more pregnancies. Food, total energy, protein, fat, and calcium intakes were highest in the two-more in urban group and lowest in the single in rural group. Working hours tended to be higher in rural residents and lower in single-person households. The single in urban group contained more smokers, people with HTN, and anti-hypertensive drug users than the other groups. Physical activity, alcohol status, prevalence of diabetes mellitus, and history of cancer were not significantly different among the groups. The prevalence of thyroid disease was significantly lower in the single in rural group. Osteoporosis prevalence was highest in the single in rural group and lowest in the two-more in urban group. The prevalence of vertebral fracture was higher in the single in rural group, although this was not statistically significant.

BMDs at all sites were significantly lower in the single in rural group than in the two-more in urban group (Table 3). After adjustment for age, BMI, number of pregnancies, duration of menopause, systolic BP, PTH, vitamin D levels, HTN, thyroid disease, working hours, 
Table 2. General characteristics of participants stratified by household size and residential area

\begin{tabular}{|c|c|c|c|c|}
\hline \multirow[b]{2}{*}{ Characteristic } & \multicolumn{2}{|c|}{ Rural } & \multicolumn{2}{|c|}{ Urban } \\
\hline & $\begin{array}{c}\text { Single } \\
(\mathrm{n}=194)\end{array}$ & $\begin{array}{c}\text { Two-more } \\
(\mathrm{n}=775)\end{array}$ & $\begin{array}{c}\text { Single } \\
(\mathrm{n}=297)\end{array}$ & $\begin{array}{c}\text { Two-more (ref) } \\
(\mathrm{n}=1,792)\end{array}$ \\
\hline Age, yr & $69.8 \pm 0.6^{a}$ & $64.0 \pm 0.3^{\mathrm{a}}$ & $68.2 \pm 0.5^{\mathrm{a}}$ & $61.5 \pm 0.2$ \\
\hline $\mathrm{BMI}, \mathrm{kg} / \mathrm{m}^{2}$ & $23.8 \pm 0.3$ & $24.2 \pm 0.1$ & $24.6 \pm 0.2^{b}$ & $24.2 \pm 0.1$ \\
\hline $\mathrm{SBP}, \mathrm{mmHg}$ & $131.4 \pm 1.2^{\mathrm{a}}$ & $129.3 \pm 0.6^{\mathrm{a}}$ & $132.0 \pm 1.1^{\mathrm{a}}$ & $127.0 \pm 0.4$ \\
\hline $\mathrm{DBP}, \mathrm{mmHg}$ & $78.5 \pm 0.8$ & $78.1 \pm 0.4$ & $78.4 \pm 0.6$ & $78.2 \pm 0.2$ \\
\hline Fasting glucose, mg/dL & $100.2 \pm 1.5$ & $99.5 \pm 0.8$ & $101.8 \pm 1.2$ & $100.9 \pm 0.6$ \\
\hline Total cholesterol, mg/dL & $199.5 \pm 2.6$ & $200.3 \pm 1.3$ & $200.8 \pm 2.2$ & $202.2 \pm 0.9$ \\
\hline Vitamin D, ng/mL & $20.8 \pm 0.5^{\mathrm{a}}$ & $19.5 \pm 0.2^{\mathrm{a}}$ & $18.4 \pm 0.4$ & $17.6 \pm 0.2$ \\
\hline PTH, pg/mL & $74.4 \pm 2.6^{b}$ & $69.7 \pm 1.2$ & $71.7 \pm 1.7$ & $68.1 \pm 0.8$ \\
\hline Age at menopause, yr & $48.0 \pm 0.37^{\mathrm{a}}$ & $48.7 \pm 0.17^{\mathrm{a}}$ & $49.0 \pm 0.31^{\mathrm{a}}$ & $49.8 \pm 0.10$ \\
\hline No. of pregnancies & $5.7 \pm 0.17^{\mathrm{a}}$ & $5.1 \pm 0.08^{\mathrm{a}}$ & $5.4 \pm 0.18^{\mathrm{a}}$ & $4.7 \pm 0.06$ \\
\hline Food intake, g/day & $900.9 \pm 31.6^{\mathrm{a}}$ & $1,055.0 \pm 18.7^{\mathrm{a}}$ & $976.0 \pm 35.2^{\mathrm{a}}$ & $1,182.6 \pm 15 \cdot 4$ \\
\hline \multicolumn{5}{|l|}{ Nutrient support } \\
\hline Total energy intake, kcal/day & $1,438.4 \pm 34.8^{a}$ & $1,583 \cdot 3 \pm 20.9$ & $1,457 \cdot 4 \pm 34 \cdot 7^{\mathrm{a}}$ & $1,586.6 \pm 15 \cdot 0$ \\
\hline Protein intake, g/day & $44.2 \pm 1.5^{\mathrm{a}}$ & $51.8 \pm 1.0$ & $47 \cdot 7 \pm 1.5^{\mathrm{a}}$ & $54.2 \pm 0.7$ \\
\hline Fat intake, g/day & $16.1 \pm 0.9^{\mathrm{a}}$ & $20.9 \pm 0.6^{b}$ & $20.1 \pm 1.1^{\mathrm{a}}$ & $24.9 \pm 0.4$ \\
\hline Calcium intake, mg/day & $377.6 \pm 25.6^{b}$ & $406.1 \pm 10.3^{b}$ & $410.2 \pm 20.0$ & $446.7 \pm 10.3$ \\
\hline Working hours, hr/wk & $18.0 \pm 1.6$ & $30.1 \pm 0.9^{\mathrm{a}}$ & $9.8 \pm 1.1^{\mathrm{a}}$ & $16.1 \pm 0.6$ \\
\hline Physical activity, high/moderate/walk & $\begin{array}{c}22 / 26 / 53 \\
(11.3 / 13 \cdot 4 / 27 \cdot 3)\end{array}$ & $\begin{array}{c}87 / 111 / 192 \\
(11.2 / 14 \cdot 3 / 24.8)\end{array}$ & $\begin{array}{c}28 / 28 / 90 \\
(9.4 / 9.4 / 30.3)\end{array}$ & $\begin{array}{c}213 / 152 / 544 \\
(11.9 / 8.5 / 30.4)\end{array}$ \\
\hline Heavy alcoholics & $5(2.6)$ & $7(0.9)$ & $5(1.7)$ & $18(1.0)$ \\
\hline Cigarette smoking, current/ex & $14 / 4(7.2 / 2.1)$ & $29 / 18(3.7 / 2.3)$ & $18 / 23^{\mathrm{a}}(6.1 / 7.7)$ & $58 / 70(3.2 / 3.9)$ \\
\hline Diabetes mellitus & $23(11.9)$ & $85(11.0)$ & $47(15.8)$ & $231(12.9)$ \\
\hline Hypertension & $87(44.8)^{b}$ & $319(41.2)^{b}$ & $148(49.8)^{\mathrm{a}}$ & $648(36.2)$ \\
\hline Anti-hypertensive drug use & $80(44.2)^{b}$ & $280(36.1)$ & $133(44.8)^{\mathrm{a}}$ & $597(33 \cdot 3)$ \\
\hline Thyroid disease & $6(3.1)^{\mathrm{a}}$ & $47(6.1)^{b}$ & $21(7.1)$ & $158(8.8)$ \\
\hline History of cancer & $10(5 \cdot 2)$ & $36(4.6)$ & $16(5 \cdot 4)$ & $85(4 \cdot 7)$ \\
\hline Osteoporosis & $114(58.8)^{\mathrm{a}}$ & $307(39.6)^{\mathrm{a}}$ & $130(43.8)^{\mathrm{a}}$ & $555(31.0)$ \\
\hline Vertebral fracture & $4(2.1)$ & $14(1.8)$ & $6(2.0)$ & $17(0.9)$ \\
\hline
\end{tabular}

Values are presented as mean $\pm \mathrm{SE}$ or number (\%). All $p$ values were obtained using the Student $t$ test or chi-square test. BMI, body mass index; SBP, systolic blood pressure; DBP, diastolic blood pressure; PTH, parathyroid hormone.

${ }^{a} p<0.01$ (statistical significance).

${ }^{b} p<0.05$ (statistical significance).

physical activity, heavy alcoholics, smoking status, daily food intake, and nutrient support, lumbar spine BMD was still significantly lower in the single in rural group than in the two-more in urban group. Total femur and femoral neck BMDs were not significantly different after adjustment for potential confounding factors.

\section{Household size, residential area, and risk for osteo- porosis and fracture}

Compared with the two-more in urban group, the OR of all the other groups for lumbar spine osteoporosis was significantly higher in the unadjusted model (Table 4). After adjustment for multiple confounding factors, the prevalence of lumbar spine osteoporosis did not differ 
Table 3. Bone mineral density according to household size and residential area

\begin{tabular}{|c|c|c|c|c|}
\hline \multirow{2}{*}{ Variable } & \multicolumn{2}{|c|}{ Rural area } & \multicolumn{2}{|c|}{ Urban area } \\
\hline & Single & Two-more & Single & Two-more (ref) \\
\hline \multicolumn{5}{|c|}{ Lumbar spine BMD } \\
\hline Unadjusted & $0.734 \pm 0.012^{\mathrm{a}}$ & $0.800 \pm 0.007^{b}$ & $0.778 \pm 0.007^{a}$ & $0.821 \pm 0.004$ \\
\hline Adjusted & $0.786 \pm 0.016^{\mathrm{a}}$ & $0.807 \pm 0.015$ & $0.819 \pm 0.015$ & $0.816 \pm 0.014$ \\
\hline \multicolumn{5}{|c|}{ Total femur BMD } \\
\hline Unadjusted & $0.716 \pm 0.010^{\mathrm{a}}$ & $0.783 \pm 0.006$ & $0.741 \pm 0.006^{\mathrm{a}}$ & $0.788 \pm 0.003$ \\
\hline Adjusted & $0.754 \pm 0.012$ & $0.769 \pm 0.011$ & $0.769 \pm 0.010$ & $0.761 \pm 0.010$ \\
\hline \multicolumn{5}{|c|}{ Femoral neck BMD } \\
\hline Unadjusted & $0.574 \pm 0.009^{\mathrm{a}}$ & $0.634 \pm 0.005$ & $0.586 \pm 0.005^{\mathrm{a}}$ & $0.639 \pm 0.003$ \\
\hline Adjusted & $0.619 \pm 0.011$ & $0.630 \pm 0.010$ & $0.624 \pm 0.010$ & $0.624 \pm 0.009$ \\
\hline
\end{tabular}

Values are presented as mean \pm SE. Data were analyzed by the complex samples general linear model. Adjustment for age, body mass index, number of pregnancies, duration of menopause, systolic blood pressure, parathyroid hormone, vitamin D levels, hypertension, thyroid disease, working hours, physical activity, heavy alcoholics, smoking status, daily food intake, and nutrient support.

$\mathrm{BMD}$, bone mineral density.

${ }^{a} p<0.01$ (statistical significance).

${ }^{\mathrm{b}} \mathrm{p}<0.05$ (statistical significance).

Table 4. Osteoporosis and fracture risk according to household size and residential area

\begin{tabular}{|c|c|c|c|c|}
\hline \multirow{2}{*}{ Variable } & \multicolumn{2}{|c|}{ Rural area } & \multicolumn{2}{|c|}{ Urban area } \\
\hline & Single & Two-more & Single & Two-more \\
\hline \multicolumn{5}{|c|}{ Osteoporosis of lumbar spine } \\
\hline Unadjusted & $3.155(2.143-4.646)^{\mathrm{a}}$ & $1.383(1.064-1.797)^{b}$ & $1.633(1.194-2.233)^{\mathrm{a}}$ & 1 (ref) \\
\hline Model 1 & $1.622\left(1.045^{-2.517}\right)^{\mathrm{b}}$ & $1.152(0.874-1.517)$ & $0.853(0.592-1.229)$ & 1 (ref) \\
\hline Model 2 & $1.667(1.083-2.565)^{b}$ & $1.137(0.861-1.502)$ & $0.879(0.610-1.266)$ & 1 (ref) \\
\hline \multicolumn{5}{|c|}{ Vertebral fracture } \\
\hline Unadjusted & $3.518(0.880-14.054)$ & $2.617(1.099-6.228)^{b}$ & $2.675(0.976-7.336)$ & $1(\mathrm{ref})$ \\
\hline Model 1 & $1.884(0.362-9.813)$ & $1.848(0.756-4.515)$ & $1.265(0.444-3.608)$ & $1(\mathrm{ref})$ \\
\hline Model 2 & $1.963(0.347-11.107)$ & $1.865(0.783-4.442)$ & $1.309(0.447-3.839)$ & 1 (ref) \\
\hline
\end{tabular}

Values are presented as odds ratio (95\% confidence interval). Data were analyzed by the complex samples logistic regression model. Model 1: adjusted for age, body mass index, number of pregnancies, duration of menopause, systolic blood pressure, parathyroid hormone, vitamin D levels, hypertension, and thyroid disease. Model 2: adjusted for age, body mass index, number of pregnancies, duration of menopause, systolic blood pressure, parathyroid hormone, vitamin D levels, hypertension, thyroid disease, working hours, physical activity, heavy alcoholics, smoking status, daily food intake, and nutrient support.

${ }^{a} p<0.01$ (statistical significance).

$\mathrm{b}_{\mathrm{p}}<0.05$ (statistical significance).

between the two-more in rural and the single in urban groups. However, subjects in the single in rural group had the highest odds of osteoporosis in the lumbar spine (OR, 1.667; 95\% CI, 1.083 to 2.565). Although the OR of vertebral fracture was higher in the two-more in rural group than in the two-more in urban group in the un- adjusted model, the prevalence of vertebral fracture was correlated with neither household size nor residential area in the adjusted model. 


\section{DISCUSSION}

We assessed whether osteoporosis was associated with household size and residential area in postmenopausal women included in the fourth and fifth KNHANES. Individuals in single-person households in rural areas had significantly lower BMD of the lumbar spine than individuals living in households with two or more people and in an urban area. In addition, individuals living alone in a rural area had significantly greater odds of osteoporosis than those living with at least one other person in an urban area, suggesting that individuals living in rural single-person households have the greatest risk of osteoporosis.

Several studies have investigated the association between residential area, household size, and osteoporosis, although the results are inconsistent. A study in southern Sweden showed that urban residents had lower bone mineral content than rural residents [14], and another study in the Lubin region of eastern Poland shows no statistically significant difference in BMD between urban and rural residents [13]. However, these studies are of a relatively small scale to clarify the association between residential area and osteoporosis. A large-scale study showed that the fracture rate is higher in rural residents of Olmsted County, Minnesota, than in their urban counterparts [12]. Although a recent study reported the association between rural residents and osteoporosis in single-person households [11], the associations between household size, residential area, and osteoporosis have not been clearly identified. In the present study, rural residents had a lower BMD in the lumbar spine than urban residents, and individuals living in single-person households in rural areas had a significantly higher prevalence of lumbar spine osteoporosis than individuals living in households with two or more people in urban areas. However, the BMDs of the total femur and femoral neck were not associated with residential area or household size. We confined the subjects of our study to postmenopausal women, which may have affected the results. Additional studies are needed to elucidate the association between osteoporosis and residential area and household size.

Dietary factors and physical activity have been associated with osteoporosis. High protein intake is associated with a lower risk of bone loss [7-9], and other stud- ies show that high calcium intake contributes to bone maintenance [10]. Regular physical activity is also associated with reduced risk of osteoporosis and osteoporotic fracture [18,19]. Although the association between living alone and nutrient insufficiency and physical activity, respectively, is unclear, one study shows that elderly individuals living alone had poor nutrient adequacy ratio relative to those living with others [6]. Furthermore, several studies have investigated the associations between residential region and nutritional status and physical activity, respectively. Rural residents have lower protein intake than do urban residents [20], and they are more sedentary and report more barriers to leisure-time physical activity than do urban residents [21,22]. In accordance with these findings, our study showed that food intake and total energy, protein, fat, and calcium intake were significantly lower in single-person households and these trends were more prominent in rural single-person households. However, our data showed that physical activity was not statistically different according to household size and residential area.

This study had some limitations. First, this was a cross-sectional study and did not identify a causal relationship between osteoporosis, household size, and residential area. Second, we divided the participants into four groups. However, because the residential area may influence household size, these groups were not independent of each other. This may have affected the results of this study. Third, subjects who had a history of steroid use or cancer, which could influence the incidence of osteoporosis, were included in this study. Fourth, factors related to household size and residential area that contribute to loss of bone mass are unclear. Despite these limitations, this study was the first to investigate risk of osteoporosis in relation to household size and residential status in a large population $(\mathrm{n}=$ 3,058) of postmenopausal women.

In conclusion, the present study showed increased risk of osteoporosis in the lumbar spine in postmenopausal women living alone in a rural area. Because few studies have investigated the relationship between living alone and health outcomes, our study suggests that osteoporosis screening are particularly important in postmenopausal women who live alone and in rural areas. 


\section{KEY MESSAGE}

1. Single households and rural residents may have a risk of various metabolic diseases.

2. Single households living in rural area had a lower bone mineral density and greater odds of osteoporosis in lumbar spine than twomore households in urban area.

3. More careful screening for osteoporosis is needed to single households in rural.

\section{Conflict of interest}

No potential conflict of interest relevant to this article was reported.

\section{Acknowledgments}

This work was supported by Biomedical Research Institute grant, Kyungpook National University Hospital (2014).

\section{REFERENCES}

1. Statistics Korea. Population and housing census of Korea [Internet]. Daejeon (KR): Statistics Korea, c1996 [cited 2016 Mar 10]. Available from: http://kostat.go.kr/portal/korea/ kor_nw/2/1/index.board?bmode=read\&aSeq=269194.

2. Statistics Korea. A household projections: 2010 to 2035 [Internet]. Daejeon (KR): Statistics Korea, c1996 [cited 2016 Mar 10]. Available from: http://kostat.go.kr/portal/korea/ kor_nw/2/2/6/index.board?bmode=read\&aSeq=255176.

3. Kramarow EA. The elderly who live alone in the United States: historical perspectives on household change. Demography 1995;32:335-352.

4. Palmer G. Single Person Households: Issues That JRF Should Be Thinking about. York: Joseph Rowntree Foundation, 2006.

5. Smith A, Wasoff F, Jamieson L; Centre for Research on Families and Relationships. Solo Living across the Adult Lifecourse. Edinburgh: Centre for Research on Families and Relationships, 2005.

6. Kim C, Park YS. Comparing health-related behaviors, food behaviors, and the nutrient adequacy ratio of rural elderly by single-elderly families vs. extended families. Korean J Community Nutr 2000;5(Suppl):307-315.
7. Schurch MA, Rizzoli R, Slosman D, Vadas L, Vergnaud P, Bonjour JP. Protein supplements increase serum insulinlike growth factor-I levels and attenuate proximal femur bone loss in patients with recent hip fracture: a randomized, double-blind, placebo-controlled trial. Ann Intern Med 1998;128:801-809.

8. Hannan MT, Tucker KL, Dawson-Hughes B, Cupples LA, Felson DT, Kiel DP. Effect of dietary protein on bone loss in elderly men and women: the Framingham Osteoporosis Study. J Bone Miner Res 2000;15:2504-2512.

9. Kim J, Kim B, Lee H, Choi H, Won C. The Relationship between prevalence of osteoporosis and proportion of daily protein intake. Korean J Fam Med 2013;34:43-48.

10. Filip RS, Zagorski J. Osteoporosis risk factors in rural and urban women from the Lublin Region of Poland. Ann Agric Environ Med 2005;12:21-26.

11. Kim J, Lee J, Shin JY, Park BJ. Socioeconomic disparities in osteoporosis prevalence: different results in the overall Korean adult population and single-person households. J Prev Med Public Health 2015;48:84-93.

12. Melton LJ 3rd, Crowson CS, O'Fallon WM. Fracture incidence in Olmsted County, Minnesota: comparison of urban with rural rates and changes in urban rates over time. Osteoporos Int 1999;9:29-37.

13. Filip RS, Zagorski J. Bone mineral density and osteoporosis in rural and urban women: epidemiological study of the Lublin region (Eastern Poland). Ann Agric Environ Med 2001;8:221-226.

14. Gardsell P, Johnell O, Nilsson BE, Sernbo I. Bone mass in an urban and a rural population: a comparative, population-based study in southern Sweden. J Bone Miner Res 1991;6:67-75.

15. Schoeller DA, Tylavsky FA, Baer DJ, et al. QDR 4500A dual-energy X-ray absorptiometer underestimates fat mass in comparison with criterion methods in adults. Am J Clin Nutr 2005;81:1018-1025.

16. Kelly TL, Wilson KE, Heymsfield SB. Dual energy X-Ray absorptiometry body composition reference values from NHANES. PLoS One 2009;4:e7038.

17. Report of a WHO Study Group. Assessment of fracture risk and its application to screening for postmenopausal osteoporosis. World Health Organ Tech Rep Ser 1994;843:1-129.

18. Gregg EW, Cauley JA, Seeley DG, Ensrud KE, Bauer DC. Physical activity and osteoporotic fracture risk in older women: study of Osteoporotic Fractures Research Group. 
Ann Intern Med 1998;129:81-88.

19. Feskanich D, Willett W, Colditz G. Walking and leisure-time activity and risk of hip fracture in postmenopausal women. JAMA 2002;288:2300-2306.

20. Campos H, Willett WC, Peterson RM, et al. Nutrient intake comparisons between Framingham and rural and Urban Puriscal, Costa Rica: associations with lipoproteins, apolipoproteins, and low density lipoprotein particle size. Arterioscler Thromb 1991;11:1089-1099.
21. Wilcox S, Castro C, King AC, Housemann R, Brownson RC. Determinants of leisure time physical activity in rural compared with urban older and ethnically diverse women in the United States. J Epidemiol Community Health 2000;54:667-672.

22. Brownson RC, Eyler AA, King AC, Brown DR, Shyu YL, Sallis JF. Patterns and correlates of physical activity among US women 40 years and older. Am J Public Health 2000;90:264-270. 